\title{
DE UNA NOCIVIDAD A LA OTRA: LA BIOÉTICA FRENTE AL DESAFÍO DE CULTIVAR SU PLURALISMO
}

\author{
Sergio Zorrilla Fuenzalida*
}

Resumen: Este texto aborda las nocividades ambiental y alimentaria como temáticas que, a pesar de sus propias características, constituyen una parte importante del universo al interior del cual la bioética se desarrolla. En este sentido las nocividades representan un desafío reflexivo y metodológico que obliga a la bioética interrogarse, incluso, sobre procesos y términos que fundamentan su accionar cotidiano. En la medida que las nocividades ambientales y alimentarias tienen una historia -reflexiva y práctica-, independiente de la bioética, con participación de actores de horizontes diversos, es preciso referirse a la experiencia acumulada estos últimos años. Como se dice en el texto, es preciso interrogarse por su puesta en relato y los resultados que ello ha provocado. Esta experiencia constituye el terreno inevitable para continuar reflexionando sobre las nocividades desde la bioética. Puesto que esta historia también da cuenta de obstáculos y dificultades con las regulaciones y juicios propuestos, ocurre que la bioética al medirse con las nocividades se mide también con una parte considerable de sí misma.

Palabras clave: Ecología, ambientalismo, nocividad alimentaria, transgénicos, regulación, pluralismo.

\section{FROM ONE HARMFULNESS TO THE OTHER: BIOETHICS FACES THE CHALLENGE OF CULTIVATING ITS \\ PLURALISM}

Abstract: This text addresses environmental and food harmfulness as issues that despite their own features constitute an important part inside the universe where bioethics develops. In this sense harmfulness poses a reflective and methodological challenge that compels bioethics to question even about processes and concepts that underlie its daily deeds. Considering that environmental and food harmfulness have their own reflexive and practical history - unrelated to bioethics-, with the participation of actors from diverse spheres it is necessary to make reference to experiences accumulated upon the latest years. As it is stated in the text, there is a necessity of questioning about its discourse and the results derived from it. These experiences constitute the unavoidable ground to keep on thinking over harmfulness from the bioethics standpoint. Since this history also reports obstacles and difficulties with already proposed regulations and value judgements, bioethics when tested against harmfulness is also being tested against an important part of itself.

Keywords: ecology, environmentalism, food harmfulness, GMO, regulations, pluralism.

\section{DESDE UMA NOCIVIDADE ATÉ UMA OUTRA: A BIOÉTICA EM FRENTE DO DESAFIO DE CULTIVAREM O SEU PLURALISMO}

Resumo: O texto aborda as nocividades ambientais e alimentícias como temas que, a pesar das suas próprias características, compõem uma parte relevante do universo dentro do qual a bioética se desenvolve. Neste sentido as nocividades representam um desafio reflexivo e metodológico que faz com que a bioética questione, inclusive, os processos e nomenclaturas que fundamentam a sua ação cotidiana. Visto que as nocividades ambientais e alimentícias possuem uma história -reflexiva e prática-, independente da bioética, com a participação de atores de vários universos, se faz necessário reflexionar sobre a experiência acumulada nos últimos anos. De acordo ao mencioando no texto, se faz necessário questionar a sua presença nos discursos e os resultados que isto tem provocado. Esta experiência constitui o inevitável terreno para que se continue reflexionando com respeito às nocividades desde a pespectiva da bioética. Pelo fato desta história também trazer à tona os obstáculos e dificuldades com as regulações e juízos já propostos, traz como consequência que ao se medir a bioética com as nocividades também se está medindo com uma parte considerável de si mesma.

Palavras chaves: Ecologia, ambientalismo, nocividade alimentícia, transgênicos, regulação, pluralismo.

* Profesor Titular Facultad de Ciencias Médicas, Universidad de Santiago, Chile. Consultor Externo Programa Regional de Bioética OPS/OMS. Chile.

Correspondencia: zorrilla@chi.ops-oms.org 
De una nocividad a la otra, tema de este texto, busca evidentemente plantear un cierto número de posiciones sobre las nocividades alimentarias y ambientales; pero, sobre todo, las aborda como una temática que incumbe y remueve profundamente a la bioética. Es decir, en la perspectiva de las implicaciones presentes y futuras que estas nocividades han tenido o debieran tener respecto de algo que llamamos la bioética o, a lo menos, del carácter y contenido de su reflexión, así como su significación como práctica social y cultural. Todo ello porque en este tema de las nocividades la magia de la palabra no existe. Todos sabemos que son muchos los discursos y las verdades y desgraciadamente, a menudo, muy pocas las soluciones satisfactorias; como también sabemos que el terreno de la nocividad se encuentra minado por intereses de todo tipo, particularmente económicos y políticos ${ }^{\mathrm{i}}$, por comportamientos ambiguos y manipuladores de los medios de comunicación y, más aún, como consecuencia de lo anterior o porque las cosas son así, por una continua/discontinua despreocupación y desparpajo de la denominada sociedad civil respecto de las nocividades.

De una nocividad a la otra, además, de procurarnos la ocasión de expresar nuestro punto de vista sobre éstas, se presenta entonces como un recorrido reflexivo en el ámbito de la bioética, origen de textos y discusiones, con múltiples entradas y salidas, entre las cuales es posible distinguir a lo menos tres, identificando y privilegiando, en el contexto de este artículo, una cuarta que se buscará legitimar al final de este texto y que se enuncia como consecuencia de las otras.

\section{La Bioética en el terreno de la nocividad}

En esta metáfora del recorrido reflexivo, la nocividad alimentaria y ambiental es, en primer lugar, un hecho (¿un hecho?), una manifestación o establecimiento de una temática urgente que exige ser reflexionada en los múltiples campos del saber donde se explicita la responsabilidad en sus distintas formas, en particular, en el espacio de la bioética. Asumiendo esta temática -simplemente por el hecho que genera artículos y discusiones y es objeto de publicaciones especializadas ${ }^{\mathrm{ii}}$-, la bioética, quiéralo o no, pone en juego una parte de su propia legitimidad. Y esto en un doble sentido: Por un lado, a través de la capacidad de interpretariii el desafío representado por la existencia de fragmentos de la realidad que se salen del «curso normal de las cosas». Lo que implica que esta interpretación debe acompañarse de la exigencia de desplegar el valor agregado supuesto por la bioética (como disciplina, como campo interdisciplinario o como ética práctica) respecto de una temática que tiene muchos otros especialistas y cultivadores.

Un examen de la literatura bioética sobre el problema permite constatar que este desafío ha sido asumido de forma desigual. En el contexto de determinados autores es constatable una contribución y un cierto desplazamiento del problema, pero, en términos generales, el mundo bioético ha continuado embistiendo la interpretación de la nocividad en la perspectiva de un programa casi adolescente: ¡terminemos con el escándalo, nada resiste al concepto, todo puede ser objeto de diálogo y consenso!

Por otro lado, en la medida en que la bioética está reconocida en casi todo el mundo como necesaria, que incluso muchas de sus instituciones son establecidas con el beneplácito de los poderes, le correspondería a la bioética «resolver» la nocividad. Resolverla quiere decir

i Sobre el particular véanse las razones por la cuales según Bush EEUU no firmará el Protocolo de Kioto. Las «razones» ambientales pasan a segundo plano y se imponen los argumentos macroeconómicos y laborales.

ii No todos los bioeticistas se han interesado en la temática, pero aún no he constatado la existencia de alguien que la declare ajena a la bioética.

iii Todos conocemos el carácter sobrecargado que tiene esta expresión. 
aquí disolverla, traducirla, volverla disponible a una cierta gestión sociocultural o bien, simplemente, transformar el estatuto de la cuestión. En todo caso, evitar su banalización, convertirla -en el contexto de la vida cotidiana-, en una temática actual y urgente, es decir, en un hecho y un acontecimiento.

La exageración de pedir a la bioética la resolución de la nocividad proviene directamente del reconocimiento público de su necesidad, del beneplácito de los poderes y de su creciente utilización en decisiones y argumentaciones públicas. Considerar la bioética como un segmento del poder que participa en la construcción del orden mundial es una discusión que cualquier bioeticista medianamente lúcido debiera estar dispuesto a debatir públicamente. Sin embargo, hablar de poder y de orden mundial y de la manera cómo las operaciones de la bioética podrían representar/imitar este poder y este orden impone decir alguna generalidad al respecto.

Es un lugar común afirmar que alrededor de la caída del muro de Berlín toma cuerpo algo como un nuevo orden mundial, se establece la configuración de un nuevo sistemamundo, como diría Inmanuel Wallerstein (1). Éste, porque no se construye más en el escenario determinado por dos o más proyectos alternativos de sociedad y porque elimina la distinción entre un interior y un exterior del sistema-mundo, se enuncia discursivamente como voluntad de poner el poder y la fuerza «al servicio del derecho y la paz» $(2, \mathrm{p} .14)$, como capacidad de «resolver conflictos», lo que implica que este orden posee la "virtud" real o supuesta de «expandir el reino del consenso que sostiene su propio poder» $(2$, p.15).

Su carácter mundial, la ausencia de un fuera o un adentro precisa de un derecho, que para asegurar la paz y arbitrar los conflictos, debe funcionar como un derecho supranacional, que sobrepasa y engloba los Estados-Nación. Respecto de este derecho, aplicado en varias circunstancias, en particular en operaciones de policía internacional (ex Yugoslavia, Iraq,
Afganistán), que es la forma que adopta la guerra en un mundo unificado, se plantea inmediatamente la determinación de la materia/substancia, del eje y del patrón de medida que lo constituye. La respuesta es simple: aquello que lo constituye como materia/ substancia se enuncia a través de valores de tipo universal, «en el Imperio, ética, moralidad y justicia son moldeadas en nuevas dimensiones» (2, p.17). «La domesticidad de los valores, los escudos detrás de los cuales presentaban su substancia moral, los límites que protegían contra la exterioridad invaso-ra, todo eso desaparece» (2, p.17).

Lo anterior procura pistas sobre la legitimidad de la bioética y, sobre todo, respuestas respecto de la moda de la ética, que en más de alguno provocaba desconcierto y zozobra. Al nivel de los discursos y de las discusiones, la bioética y la ética participan de la elaboración/identificación de estos valores de tipo universal. De ahí una parte de su complicidad con el orden. Es evidente que esta comprensión sobre la moda de la ética no elimina la zozobra y el malestar de algunos, sólo los desplaza, concentrándolos, en el contexto del orden mundial, en preguntas tales como: "¿Quién decidirá sobre las definiciones de orden y justicia a través de la expansión de esta totalidad en curso? ¿Quién podrá definir el concepto de paz? ¿Quién será capaz de unificar el proceso de suspender la historia y denominar justa esta suspensión?» (2, p.17).

En segundo lugar, este recorrido metafórico designa también una operación interna. Una vez que la decisión de interpretar se ha impuesto, que la cartografía de la bioética se ha modificado, en principio para acoger la nocividad, se trata de establecer correlaciones entre los problemas y los conceptos y/o modelos desarrollados por la bioética con el fin de evaluar $y$, eventualmente, proponer regulaciones. Esta operación, sin embargo, puede efectuarse de dos maneras: por un lado, puede limitarse a traducir las nocividades en un lenguaje ético, con la esperanza de asociar los nudos decisionales con principios éticos, en 
principio consensuados y legitimados. Lo que sólo puede ser satisfactorio y adecuado a la resolución de la nocividad si y solamente si una serie de supuestos se constatan. Por ejemplo:

a) Que exista un espacio público real de discusión y que los discursos de la bioética sean una fuente de enriquecimiento de este espacio público. Lo que, sin mala fe, todo el mundo puede aceptar calificar como un enorme supuesto. No sólo porque los medios de comunicación, que monopolizan este espacio público, son a menudo monopólicos y poco plurales, a lo menos en nuestra Región, sino porque, además, producen la información como un espectáculo y una forma de consumo, es decir, alejados del imperativo de construir un espacio público, de donde emerja lo razonable.

b) Que las decisiones financieras y comerciales dependan de este teórico espacio público, el cual tendría el poder de sancionar moralmente o, que dependan de un espacio cultural normativo, con el cual la bioética estaría conectada directamente. Lo cual también es un supuesto por varias razones. Primero, porque la idea de un espacio público en el mundo actual es casi un ideal trascendental, sin mayor contenido material. Segundo, porque una buena parte de las nocividades son el resultado de un proceso productivo, en el cual los productores son ontológicamente más activos y creativos que los consumidores. Lo que quiere decir que tienen el privilegio "ontológico" de transformar el mundo. Finalmente, porque la idea de cultura como un recurso perenne de lo razonable es también difícil de aceptar. Al respecto Noemi Klein señala que: "Hacia mediados de la década de 1990, empresas como Nike, Polo y Tommy Hilfiger ya estaban en condiciones de pasar a la etapa siguiente en lo relativo a las marcas: ya no sólo referirlas a sus productos, sino también a la cultura del entorno... Se trataba de absorber ávidamente ideas e iconografías culturales que sus marcas pudieran reflejar proyectándolas otra vez en la cultura como 'extensiones' de las mismas...En efecto, si no la intención original, de la creación más moderna de las marcas es poner a la cultura anfitriona en un segundo plano y hacer que la marca sea la estrella. No se trata de patrocinar la cultura, sino de ser la cultura." (3, pp.5658).

c) Que los discursos de la bioética puedan alimentar a sectores de la sociedad que buscan efectivamente regular la nocividad, en particular, por ejemplo, a las asociaciones de los consumidores, lo que me parece una pista importante, aunque aquí entramos en la alternativa que busco legitimar en este texto.

En realidad pareciera ser que la idea de eficacia que precede el establecimiento de correlaciones entre principios/modelos y temáticas, se sostiene en la búsqueda de reforzar una cierta visibilización de los problemas, identificados o denunciados por otros actores sociales. Esta eficacia se sostendría en el paradigma que se desprende del nuevo orden mundial. Éste se presenta como una "totalidad sistémica (que) tiene una posición dominante en el orden global... desarrollando una integración de actores que parece ser lineal y espontánea... Todos los conflictos... empujan efectivamente hacia delante el proceso de integración... Cada movimiento está fijado y puede buscar su propio espacio designado sólo dentro del propio sistema, en la interrelación jerárquica que le ha sido acordada" (2, p. 14). Es evidente que en este paradigma "la imperfecta coincidencia... entre el nuevo poder central y el campo de aplicación de su regulación, no conducen a una crisis o parálisis, sino que meramente fuerza al sistema a minimizarlas y superarlas" (2, p.14).

Por otro lado, esta operación interna de correlación entre problemas y principios/ modelos puede situarse en otra constelación si permanece atenta a la posibilidad que caracteriza al sistema de minimizar las dificultades o superarlas en función de su propia lógica. O si la reflexión rechaza estructurarse en torno a lo que Jean Ladrière denomina «un procedimiento descendente que consiste en transitar de un principio a sus consecuencias y cuyo modelo más apropiado es, sin duda alguna, la deducción lógica». Y busca orientarse en uno de tipo «ascendente, que parte 
de los datos concretos para progresar hacia sus condiciones de existencia» (4, p.201). En este último caso nos encontramos muy lejos de una simple relación bi-unívoca o de la simple esperanza de una eficacia misteriosa que resultaría de la conexión casual de variables grandilocuentes. La correlación podría devenir una instancia de develación de realidades, más allá de toda tentativa ideológica, posibilitando la búsqueda de otras conexiones entre lo que se piensa y lo que se vive, entre lo que se postula y los malestares que dan cuenta de las insatisfacciones, de déficits de los sistemas políticos, al interior de los cuales vivimos.

En tercer lugar, la operación interna de la bioética consistente en establecer correlaciones, genera discursos, polémicas y disensiones que, al margen de ciertas temáticas emblemáticas, se mantienen en el ámbito académico, sin grandes sobresaltos y sobre todo, sin oponerse a la manera un poco light, como a menudo se comprende el pluralismo. El análisis de estos discursos y polémicas no puede ser exhaustivo, aunque su ilustración parece necesaria en la perspectiva de este texto. Brevemente examinaré dos formas de aproximación de los problemas. La primera de ellas se relaciona con la temática de la nocividad alimentaria $\mathrm{y}$, específicamente, con los alimentos genéticamente modificados. Se trata de un texto de Javier Gafo, Riesgos y ventajas de los alimentos transgénicos (5).

El artículo de Gafo está lleno de afirmaciones generales que, normalmente, podrían ser compartidas en una conversación descontextualizada del problema, tales como: "Suelo repetir profusamente que la buena ética después de todo comienza con buenos datos. En el tema que nos ocupa, la preeminencia y la prevalencia de los datos científicos constituyen un esencial punto de partida y las conclusiones de los especialistas... van a jugar un papel básico en la ponderación ética» (5, p.78); «Ni la biotecnología ni la transgénesis son una realidad nueva, sino que tienen tras sí una larga historia, que arranca desde los albores del Neolítico... Lo nuevo es la modificación directa del genoma de los seres vivos y la introducción de factores genéticos, incluso de especies muy distantes en el árbol filogenético» (5, p.p.7879); Desde el punto de vista de los riesgos, «inseparables de todo proceso científico», Gafo se expresa en los siguientes aspectos: «la pérdida de biodiversidad», "la incidencia de las plantas transgénicas en los equilibrios ecológicos de los distintos hábitats», "las posibles consecuencias negativas de los alimentos transgénicos en los humanos» (5, p.79); en el contexto de estos riesgos «es exigible la información al consumidor sobre la procedencia del producto, con la conocida etiqueta del carácter de aquéllos. El énfasis en el consentimiento informado en los temas de Bioética debe extenderse igualmente a estos alimentos» (5, p.79); Desde el punto de vista de las «grandes» ventajas: "Es necesaria una nueva revolución verde que elimine los defectos y limitaciones de la anterior y que pueda significar un incremento en la producción. Cuando las posibilidades de suelo cultivado y de agua se encuentran en los límites y la humanidad ha 'celebrado' en el 1999 el nacimiento del niño 6.000 (millones), parece una utopía pensar que la agricultura orgánica o 'biológica' pueda ser algo más que un cierto lujo de los habitantes de los países ricos. Deben subrayarse los posibles efectos positivos de las plantas transgénicas para, al menos, paliar las consecuencias negativas de la revolución verde anterior: el ahorro económico y medioambiental consecuentemente con una menor utilización de los abonos químicos y de los productos pesticidas en insecticidas". Finalmente, el texto que citamos, concluye, de acuerdo con la postura de la Revista Nature, que «la mayoría de los científicos creen que tales riesgos (a la salud) son ampliamente hipotéticos y que las habituales medidas de seguridad son adecuadas» (5, p.80).

Nuestros comentarios serán breves y nuestras observaciones críticas apuntan sobre todo a un estilo de aproximación al problema, dado que no sabemos si Gafo abordó con mayor detención en otros textos el tema que nos 
interesa. Sin embargo, sorprende inmediatamente la ausencia de informaciones sobre el contenido del fuerte debate de los transgénicos, anunciado en las frases introductorias. O más bien se tiene la sensación de que es posible ahorrarse este debate a través de la simple retranscripción de la posición adoptada por la Revista Nature. También sorprende, en un texto escrito a lo menos en 1999, la ausencia de referencia a las «vacas locas» en una discusión que ha sobrepasado el círculo de los especialistas, sobre la alimentación y su regulación, así como el desconocimiento o la falta de interés por las dificultades políticas generadas respecto de la exigencia del etiquetaje; sorprende, en resumen, la falta de contextualización de un problema que convoca y se nutre del entrecruzamiento de varias temáticas. En este sentido es posible considerar casi como un ultraje la utilización de argumentos a favor de los transgénicos que se sostienen en aspectos que dan cuenta, en otro universo de la discusión, de la crisis ambiental, tales como la escasez del agua y la crítica a los fertilizantes químicos.

En realidad, en la perspectiva del «estilo» de aproximación al problema o, dicho de una manera mucho menos trivial, desde el punto de vista de la pertinencia de la intervención del discurso bioético en el debate que se instaura sobre los transgénicos, se tiene la sensación que el texto que comentamos se caracteriza por: 1) considerar como un dato indiscutible en el dossier de los transgénicos la posibilidad y la facilidad de separar lo bueno de lo malo; 2) introducir en este debate la bioética, como si ella constituyera un espacio social legitimado donde el ejercicio de la racionalidad se encuentra asegurado; 3 ) reducir las oposiciones y divergencias sobre el tema a simples reacciones de miedo y/o a la dificultad de acceder a la información correcta; 4) y, entender las divergencias como incapacidad de poner en relación distintos niveles de discurso, considerarlas, por lo tanto, como fácilmente superables a través de afirmaciones discursivas, reforzadas evidentemente por mecanismos existentes de regulación. En pocas palabras no considerar la dificultad planteada por los transgénicos como un acontecimiento capaz de generar series causales divergentes en el mundo actual. Es decir, sólo entenderlo como un tipo de gestión compleja en el marco de las lógicas existentes.

En este estilo de aproximación a los problemas, donde fácilmente se olvida que la historia del siglo pasado es rica en acontecimientos ambiguos y de resultados no esperados, se constata un empobrecimiento de la noción de fundación o simplemente del estatuto de la interpretación. Los fenómenos sociales y culturales que plantean problema no resuenan al interior del espacio de la bioética como un desafío para la interpretación y la recreación del sentido, ésta se confunde con el lenguaje del experto, reduciéndola a un horizonte de principios que permite establecer simples relaciones biunívocas.

Nos encontramos en otra dimensión del trabajo reflexivo de la bioética cuando nos referimos a algunas discusiones respecto del pensamiento de Jonas. En relación con éste nos aproximamos a la temática ambiental. Aquí nuestro interés no se limita a los supuestos que legitiman y generan un estilo de intervención en lo público de la bioética; se relaciona esencialmente con el destino de la problemática (su urgencia, las medidas que ella implica) tan pronto como la reflexión se despliega.

En particular, quisiéramos referirnos a las críticas que un autor como G. Hottois propone respecto de Jonas. Hottois plantea cuatro observaciones críticas que limitan la pertinencia del discurso de Jonas (6). La primera se estructura en torno a la idea de fundación: "Jonas estima que una ética a la altura de los desafíos y de los riesgos... de la acción tecnocientífica debe ser fundada absolutamente y universalmente» (6, p.14). Sólo dicha fundación sería capaz de inspirar las medidas que se imponen. El problema con dicha fundación filosófica, "es que ella se ha convertido hoy día en una empresa... arriesgada, sospechosa y criticable, que a 
muchos filósofos aparece como de otra época» (6, p.14). Esta observación efec-tivamente se justifica en la perspectiva de la filosofía del siglo $\mathrm{XX}$, a pesar de que muchos bioeticistas prefieren aún ignorar dicha dificultad.

La segunda observación crítica señala que «la imagen de la naturaleza que guía la filosofía de la naturaleza que Jonas elabora en la articulación de su ontología del ser como bien y de su ética de la responsabilidad, no se encuentra a la altura de la tecnociencia y del cuestionamiento radical de la representación tradicional de la naturaleza... Su concepto de naturaleza evolutiva permanece extraordinariamente limitado, antropocéntrico... Se trata, en resumen, de conceder lo menos posible a la desmesura cósmica, la que es el correlato real de la tecnociencia, de darse una naturaleza evolutiva en acuerdo con la finitud humana» (6, p.16).

La tercera observación crítica se desarrolla en torno a la pregunta: ¿Preservar la condición humana? El texto que citamos señala: "Como la mayoría de los pensadores de sensibilidad religiosa, Jonas tiene una comprensión correcta de la tecnociencia contemporánea: se juega en ella... la existencia y... la esencia de la humanidad. Su 'dimensión' es por lo tanto 'ontológica' (lo que no quiere decir que ella despliega e incluso presupone una ontología: al contrario, precisamente) y no simplemente instrumentalista y benignamente antropocéntrica» (6, p.19). Pero una vez reconocida dicha dimensión, "Jonas sólo percibe el lado absolutamente negativo, apocalíptico. ¿Por qué? Una vez más, porque cree disponer la respuesta a la pregunta ¿Qué es el hombre?" y rechaza también de considerar como parte integrante -y desintegrante- del hombre, la indefinición, el abismo, la nada; lo que permite que el ser humano se interrogue radicalmente sobre su ser, con el fin de modificar libremente su condición». Es cierto que Jonas reconoce que el ser humano es creador. Pero el hombre sólo puede ser creador en el campo de lo simbólico.
En esta visión de las cosas, el «mal es la utopía, es decir, la voluntad de escapar a esta ambivalencia de la condición humana... Esta voluntad... constituye el único Mal auténtico, es decir, el mal radical... Jonas ve y rechaza de ver al mismo tiempo, que la ambivalencia suprema-que también se encuentra en el corazón de la religión y de la filosofia-es precisamente aquella con la cual la humanidad se relaciona consigo misma, su condición. Esta ambivalencia no sería ambivalencia, es decir, tanto positiva como negativa. Ella sería completamente peligrosa y mala» $(6, \mathrm{p} .21)$.

La última observación crítica concierne a la relación con la política. Los argumentos al respecto son bastantes conocidos: "Si la ética de responsabilidad es tan perfectamente fundada y si la situación es tan apocalíptica como lo pretenden, entonces los tiempos están maduros para una politica de salvación humana autoritaria, que podría utilizar los medios mejores y más eficaces... se trata de establecer una autoridad-denominada 'clarificada y sabia', es decir, en los hechos inspirada por la heurística del miedo y limitada al valor de preservación absoluta del hombre natural-cultural-asumiendo al nivel de la humanidad la responsabilidad del porvenir de la humanidad... En realidad 'El principio de responsabilidad', a causa de su argumentación de tipo fundamentalista, conduce a un resurgimiento del mito del Filósofo-Rey, con una desmesura sin igual, puesto que no se trata solamente de gobernar la Ciudad a la luz de un arquetipo ideal existente en sí mismo, se trata de proteger también la existencia del arquetipo, es decir, 'la imagen de la humanidad' que sólo existe porque hay seres humanos que la conciben tal y tanto tiempo como ellos existirán» (6, p.p. 22-23).

Es cierto que "Jonas plantea un problema real: vista la extraordinaria complejidad de la civilización planetaria en la época de la tecnociencia, ¿Es la democracia una forma politica viable? ¿Podemos esperar del ciudadano medio una visión inmediata- 
mente clara de los problemas cuya dimensión multi-factorial exigen la participación de múltiples disciplinas y cuyo cálculo de implicaciones se simula, por lo peor y lo mejor, con la ayuda de grandes computadoras? La respuesta es evidentemente no. Pero la solución de recambio no es tan evidente... Su solución se reduce, de manera grosera, en confiar la dirección y la decisión a los expertos virtuosos. Es perder de vista que, en estas materias, los expertos también se contradicen y que el debate debe, de todas maneras, mantenerse a su nivel, salvo de estimar que en la 'duda mejor vale abstenerse'» (6, p.24).

En un texto más reciente (7) Hottois vuelve sobre algunos de los tópicos anteriores. Previamente explicita algunos de sus supuestos - práctica saludable en el ámbito de una discusión pluralista-, en particular, el antropocentrismo metodológico, señalando que "todo discurso, toda verdad, toda norma siempre reenvía a una tradición de humanos, a una comunidad, a un o a individuos. La afirmación que una verdad o un dogma son absolutos es siempre también la afirmación de seres humanos que dicen poseer esta verdad gracias a una revelación o a una intuición sobre humana, trascendente o trascendental» (7, p.42). En dicho marco, que le permite relativizar y contextualizar todos los fundamentalismos y absolutismos, arremete contra la ecología profunda y el biocentrismo que le parecen un nuevo ejemplo de fundamentalismo, los que podrían eventualmente justificarse en el nombre de una retórica necesaria frente al desafío de los problemas ambientales. Sin embargo, la acusación de fundamentalismo a ciertas corrientes del ambientalismo, acusación muchas veces dirigida también a grupos ecologistas o verdes que se han comprometido en la vida política contingente, no es necesariamente una manera de abandonar la temática ambiental. Sobre el particular Hottois señala que es posible refutar la idea de que «sólo una posición bio o zoo-centrista... es apta a proteger eficazmente lo vivo. Los hombres pueden perfectamente decidir de proteger la naturaleza a partir de una posición antropocentrista puesto que, simplemente, se ponen de acuerdo, por múltiples razones, en tal voluntad de salvaguardar y proteger, ya que saben que es su responsabilidad. Por otra parte, tendrán tanta más consciencia de su responsabilidad... puesto que sabrán que esta salvaguardia no es garantizada por cualquier orden esencial y fundamental» (7, p.42).

En el contexto de una filosofía de la bioética -como superación de las aporías que se desprenden de la crítica a las posiciones políticas de Jonas-, es posible pensar que ciertas instituciones generadas por ésta pueden servir de modelo para adoptar posiciones eficaces, en el tiempo oportuno, por ejemplo, respecto de una temática como la ambiental, sin ignorar el pluralismo y el multiculturalismo. Sobre el particular Hottois señala que «en los comités de ética pluridisciplinarios y pluralistas, tal como los concibo y como he podido experimentarlo, la discusión igualitaria entre individuos o grupos, con convicciones morales, filosóficas y religiosas muy diferentes, aunque capaces de expresarse de forma argumentada... no conduce a la conclusión que todo es equivalente y que todo es indiferente.» (7, p.43).

Es evidente que gran parte de las posiciones anteriores de Hottois, que comparto en muchos aspectos, buscan configurar una bioética que sea capaz de regular la tecnociencia, sin ignorar: 1) que la tecnociencia es un acontecimiento histórico, antropológico e incluso inscrito en la naturaleza, de forma inevitable; 2) que entre las referencias que permiten una cierta regulación es necesario reconocer y promover dos tipos de fundamentos o de hitos que permiten el desarrollo de un relato en coherencia con las otras realidades que nos constituyen. Por un lado el pluralismo, que es al mismo tiempo, pluralismo cultural y pluralismo de valores. Por el otro, el convencimiento que no es posible regular la tecnociencia-donde regulación y tecnociencia tienen por objeto reproducir y construir el mundo-si se corre el riesgo de ignorar y castrar de manera duradera, por ejemplo, en el nombre 
de una heurística del miedo, la fuente de creatividad, de alteración y de novedad constitutiva del ser humano.

Sin embargo, en la perspectiva de nuestro texto y reconociendo que respecto de cualquier autor la prudencia recomienda el conocimiento más vasto de sus escritos, lo que no es mi caso, algunas dudas me surgen. La primera de ellas se enuncia a través de dos preguntas: ¿El pluralismo como hito $\mathrm{y}$ fundamento de evaluaciones, de juicios, de opciones y regulaciones, engloba también la temática de los intereses económicos? ¿Estos intereses, representantes sin duda alguna, de una cierta sensibilidad respecto del mundo, tienen el mismo estatuto material que las otras sensibilidades explicitadas con ocasión de un problema puntual? Es evidente que el estatuto de los intereses económicos es central, puesto que en aquello que puede ser regulado en el caso de las nocividades alimentarias y ambientales existe un nudo central que se expresa y se puede leer al nivel de intereses económicos, de lógicas económicas y de problemas de poder.

La segunda observación se relaciona con las instituciones bioéticas. Las preguntas que me parecen aquí evidentes son las siguientes: ¿Son estas instituciones capaces, por ejemplo, de cambiar la política de Bush respecto del Protocolo de Kioto, laboriosamente elaborado por otra parte, en el respeto de los distintos intereses mundiales? ¿La capacidad de evaluación y juicio de estas instituciones, justamente consideradas como figuras privilegiadas de lo razonable, son realmente representativas de las sociedades contemporáneas? Plantearse estas preguntas no debe entenderse como una crítica a las esperanzas vehiculadas por la bioética. Solamente buscan contextualizar su capacidad de acción, sin olvidar por supuesto la noción de Kairos o del tiempo en que la acción es oportuna, con el fin de evitar que la reflexión generada por la bioética se tome a sí misma como modelo de la realidad existente y sus discursos sean acompañados de la ilusión de creer poder resolver mágicamente los problemas, gracias a un cierto poder de la enunciación.

Finalmente, es cierto que toda argumentación corre el riesgo de fundamentalismo y de absolutismo, sobre todo cuando lo que se busca promover a través de esta argumentación es valorado psicológicamente y considerado como un gran desafío. Este riesgo es aun mayor cuando esta argumentación busca aumentar su fuerza retórica y persuasiva por medio de modelos fundacionales de tipo trascendental, que dejan al margen de la discusión los mismos fundamentos. Se podría afirmar que también es posible argumentar sobre bases inmanentistas, es decir, en el contexto de una lógica de actores sociales. Lo que también podría contribuir a la generación de una fuerza social, extremadamente persuasiva. Es claro que el destino de esta argumentación no sería necesariamente el comité de ética, sino que la sociedad; es también claro que una argumentación de este tipo, a pesar de ser elaborada en el campo de la bioética, tendría por objeto alimentar la política y lo político. Esta propuesta no es utópica puesto que un fenómeno de este tipo ya se ha producido, gracias al entrecruzamiento, por ejemplo, de contenidos específicos de la bioética con la organización de personas viviendo con VIH/ SIDA, a fin de proteger los enfermos de los riesgos de la discriminación.

En este punto sería también posible conceder un cierto estatuto a una dimensión del pluralismo a menudo ausente en las discusiones, aunque extremadamente importante en el campo de las nocividades. Cuando un bioeticista afirma, por ejemplo, que la agricultura orgánica es un lujo de ricos y que el verdadero problema lo plantean aquellos que no tienen nada que comer, además de funcionar como un filósofo de viejo cuño, excluye de la discusión a quienes piensan de manera diferente. La reivindicación de una agricultura orgánica por razones emotivas, por sensibilidades específicas o por preferencias 
estéticas preserva esta opción como una posibilidad para el conjunto de la humanidad. En realidad existen sensibilidades que no son necesariamente representadas por las familias espirituales, que el debate bioético promueve y que se legitiman a través de complicadas y nebulosas opciones valóricas.

\section{¿Hechos?}

Quienes consideramos las nocividades alimentaria y ambiental como un problema real y urgente tendemos a pensar estas temáticas como si constituyeran un hecho innegable; más aún, tendemos a considerarla como un acontecimiento que debiera provocar nuevas aventuras en el campo de la reflexión, incluso en el ámbito de la bioética, tan aparentemente empaquetada por ciertas prácticas literarias. Nos indignamos, de cierta manera, frente a la indolencia de muchos y comprendemos poco la discontinuidad con que las nocividades aparecen y desaparecen en las agendas públicas, políticas o reflexivas. Sin duda, de cierta manera, nos equivocamos. La experiencia es concluyente, las nocividades también exigen la puesta en relato con el fin de comenzar su lento recorrido que las convertirá en una tema central de la discusión pública; también, las nocividades tienen necesidad del trabajo representado por las mediaciones de todo tipo, con el objeto de ocupar un lugar en el contexto de las redes sociales que conforman el cuerpo social. Esto es una verdad o lo era hace muchos años atrás cuando la temática era aún incipiente.

Esta puesta en relato ha podido optar entre varias vías posibles. Su traducción a través de los diferentes discursos profesionales tiene la enorme garantía de introducir la temática de la nocividad inmediatamente en las redes de discursos que constituyen el cuerpo social.

En una visión funcional e inocente de las redes sociales se podría haber pensado que esta puesta en relato tarde o temprano alcanzaría sus objetivos. Sin embargo, este resultado no es evidente en la perspectiva de las transformaciones implicadas y esperadas por muchos respecto de las nocividades. Lo acontecido con el Protocolo de Kioto y la historia de los transgénicos muestra que las cosas son relativamente o realmente diferentes. La inflación constante de los discursos, la manía consistente en generar nuevos caminos de interpretación de la realidad en función de divergencias mínimas, sin el ánimo ni la preocupación de producir una coherencia que permita situarnos en el mundo, nos hace dudar si la exigencia de poner en relato está al servicio del establecimiento de un hecho, de su necesaria visibilidad. Nos obliga a plantearnos si esta puesta en relato, por razones antropológicas y políticas profundas, no depende de usos y normas, de redes y prácticas discursivas y materiales que la apremian, la limitan, le imponen la exigencia de una cierta complicidad con otras lógicas existentes. En cuyo caso el indicio (8) de realidad de un hecho depende cada vez más de quienes o de aquello que posee un poder jamás visto en la historia, es decir, de los medios de comunicación. La incapacidad de un hecho o de un acontecimiento de provocar lo que de ellos se esperaba se explica por su incapacidad de penetrar y comunicar con la vida cotidiana, la que en un acto de objetivación de sí misma podría alterar incluso la geometría en que se ordenan y se distribuyen las redes de discursos que conforman el cuerpo social.

El carácter casi subversivo que la noción de acontecimiento tenía en ciertos autores, en la medida en que esta noción procuraba una nueva razón de ser al pensamiento crítico extraviado en la denuncia de una ideología que sólo era ilusoria para los pensadores críticos (9), se fragiliza en el marco del mundo actual. Marc Augé nos dice: "'Acontecimiento mediático'; esta expresión de nuestros dias puede parecer un pleonasmo. Si tenemos la sensación de que siempre está ocurriendo algo en alguna otra parte, es porque estamos 'informados' de ello, como se suele decir. Desde ese momento nos preguntamos (aunque la respuesta sea incierta) qué distancia tomar, qué punto de vista hay que retener, qué oreja hay que tapar para discernir, detrás del 
estrépito y el estruendo de la actualidad, el ropaje disimulado y los cuchicheos de la historia en marcha». (10, p.16). Un poco más adelante el mismo Augé agrega: "Sobre el acontecimiento ya no sabemos qué decir, ni tan siquiera si continúa siendo un acontecimiento. Las novedades cotidianas... abundan. Los medios de comunicación, en cierto sentido, hacen que los acontecimientos existan o no» (10, p.127).

En otro texto Marc Augé aborda la temática de la ficción, más exactamente de un nuevo régimen de la ficción, como una pista para entender lo que adviene con hechos $y$ acontecimientos. Un nuevo régimen de la ficción busca dar cuenta de un cambio en «las condiciones de circulación entre lo imaginario individual (por ejemplo, los sueños), lo imaginario colectivo (por ejemplo, el mito) y la ficción (literaria o artística, puesta en imagen o no)... A través de esta temática se plantea la amenaza que hace pesar sobre lo imaginario la 'ficcionalización' sistemática de que es objeto el mundo» (11, p.19). Para Augé «todas las sociedades han vivido en lo imaginario y por lo imaginario. Digamos que todo lo real estaría 'alucinado' (sería objeto de alucinaciones para los individuos o los grupos) si no estuviera simbolizado, es decir, colectivamente representado. La cuestión particular se refiere al hecho de saber cuál es nuestra relación con lo real cuando las condiciones de la simbolización cambia» (11, p. 21).

Augé esquematiza la vida de las sociedades en el ámbito imaginario a partir de un triángulo cuyos vértices son constituidos, en la parte superior por el Imaginario y memoria colectivo (IMC) y, en la base, por el Imaginario y memoria individual (IMI) y por la creaciónficción $(\mathrm{CF})$. En este triángulo se producen evidentemente relaciones permanentes. "Lo imaginario y la memoria colectivos (IMC) constituyen una totalidad simbólica por referencia a la cual se define un grupo y en virtud de la cual ese grupo se reproduce en el universo imaginario generación tras generación. El complejo IMC ciertamente da forma a los mundos imaginarios y a las memorias individuales... Asimismo ese complejo es una fuente de elaboraciones narrativas» (11, pp.76-77).

Por otra parte «la ficción puede ser para la imaginación y la memoria del individuo la ocasión de experimentar la existencia de otras imaginaciones y de otros universos imaginarios. Pero esta experiencia se basa en la existencia de una ficción reconocida como tal... y se basa asimismo en la existencia de un autor reconocido como tal, con sus características singulares, un autor que por eso establece con cada uno de los que constituyen su público un vínculo virtual de socialización» (11, p.131). Se podría agregar que «todo proceso de ficción identificable constituye un principio de 'librepensamiento'en relación con las representaciones de lo imaginario colectivo... En este sentido, la ficción reconocida como tal es esencialmente liberadora, sólo que la libertad que ella procura está en tensión con los imperativos respectivos de los dos ámbitos imaginarios que la estimulan y la limitan a la vez» (11, p.133).

En el nuevo régimen de la ficción «la condición de la ficción y el lugar del autor están... alterados: la ficción lo invade todo y el autor desaparece. El mundo está penetrado por una ficción sin autor» (11, p.134) Más aún en la condición postmoderna o sobremoderna «Todos los antiguos universos imaginarios colectivos tienen ahora el carácter de ficción. Pero, desde el momento en que el polo de lo imaginario colectivo está desocupado, la relación de lo imaginario individual con el polo IMC... ya no tiene relación de ser. Ante sí, lo imaginario individual no tiene más que la ficción. Pero la ficción también ha cambiado, puesto que ya no tiene intercambio alguno con el polo desocupado por IMC. El esquema se simplifica. La nueva ficción, que llamaremos 'ficción-imagen', se sitúa a media distancia de los anteriores polos IMC y CF, como si ambos se hubieran desplazado hacia una nueva posición de equilibrio. El polo IMI, directamente ligado a ese nuevo punto de 
equilibrio, sólo tiene relación con él. Informado únicamente por la ficción-imagen, el yo que ocupa el antiguo polo de lo imaginario y de la memoria individuales (IMI) puede considerarse 'ficcional'» (11, pp.135,36).

En realidad "el yo ficcional se ve permanentemente amenazado de quedar absorbido por la ficción-imagen, que se presenta simultáneamente como lo imaginario colectivo y como ficción, siendo así que la ficción-imagen debe su existencia a la eliminación de estas dos últimas instancias, a la desaparición simultánea de la historia y del autor» (11, p.136). En este contexto «el yo ficcional... es un yo sin relaciones y por eso mismo sin soporte de identidad, es un yo que corre el riesgo de quedar absorbido por el mundo de imágenes en el que él cree poder encontrarse y reconocerse» (11, p.151).

Sobre la base de este breve recorrido podemos volver sobre el título de este acápite y entender, sin por ello consolarnos, la dificultad de convertir en un hecho o en un acontecimiento la temática de la nocividad alimentaria y ambiental. Lo que, a su vez, evidentemente sobredimensiona el ejercicio supuesto por la puesta en relato o por la argumentación que busca instaurarla como una temática pública.

Esta especie de constatación antropológica permite identificar una serie de nuevos aspectos importantes: 1) Es evidente que conviene discutir y polemizar con cualquier forma de fundamentalismo o absolutismo, pero guardando la serenidad suficiente para escuchar $\mathrm{y}$ eventualmente reflexionar sobre las imposibilidades y dificultades antropológicas y políticas que pueden eventualmente legitimarlos. Estos pueden ser el signo de un acelerado déficit simbólico, tanto a nivel local como en la manera como otras culturas se relacionan con el orden mundial. Es fácil denunciar riesgos e incoherencias. Es también importante constatar los sesgos culturales y políticos sobre los cuales se desarrolla nuestro propio pluralismo; 2) La regulación de temáticas tales como las nocividades es mucho más laboriosa, en principio, que las temáticas que se desprenden de la tecnociencia que exigen una regulación para aceptar su introducción en el cuerpo social. El carácter construido, de cierta manera legítimo, de esta última salta a la vista; 3) La puesta en relato de las nocividades, dada las estructuras antropológicas y políticas que vuelven visibles o invisibles hechos y acontecimientos sólo puede asumirse plenamente cuando se comprende también como una propuesta educativa, pero en una perspectiva en la cual lo educativo y lo político se conectan íntimamente. Esta puesta en relato, en la medida que las nocividades atraviesan las instituciones, las redes que éstas constituyen y las lógicas que las sostienen puede perfecta y legítimamente no satisfacerse plenamente de una exigencia analítica. Contiene inevitablemente propuestas y temas donde se juega la temática del sentido.

\section{Observaciones sobre la nocividad ambien- tal}

La puesta en relato de la nocividad ambiental tiene una larga historia, evidentemente anterior a la bioética. Respecto de esta historia es importante saber lo que eventualmente la bioética ha hecho, lo que puede hacer y de manera menos trivial, cuál es el espacio y la importancia que se concede a la problemática ecológica en el presente y el futuro.

La historia de la puesta en relato de la nocividad ambiental es central, a lo menos, respecto de dos temáticas: en relación con el devenir hecho o acontecimiento de la temática ambiental o de su inscripción en el sistemamundo como una exigencia transversal, dotada de caracteres propios y respecto del estatuto de ciertas argumentaciones/fundaciones, productos privilegiados de la bioética, lo que evidentemente plantea la relación de ésta con la sociedad y la política.

La historia de esta puesta en relato es colosal en escritos y rica en experiencias de todo tipo que han involucrado la mayor parte de los 
saberes y prácticas existentes; ilustrativa de enseñanzas respecto de la política, de las relaciones de ésta con las lógicas económicas y sociales predominantes e incluso, de la perennidad de la ideología y de la ilusión, como fenómenos actuales, tanto individuales como colectivos.

Pretender abarcar esta historia en un texto como éste sería injurioso, equivalente a presumir competencias que no poseo. Afortunadamente algunos escritos (12) facilitan la tarea y permiten abordar, con cierta seguridad, el tema de forma esquemática. Esta historia se construye y se desarrolla en la perspectiva de dos corrientes con contenidos diferentes y efectivamente antagónicos: el ecologismo y el ambientalismo. Este último, es necesario destacarlo, se impone por el momento.

Es posible representarse el ecologismo como una constelación que reúne en un mismo proceso a pensadores y a generaciones de jóvenes, fundamentalmente en los países desarrollados, a través de continuas movilizaciones contra lo nuclear, la defensa de lo rural, contra la impunidad de catástrofes petroleras u otras, la caza indiscriminada de determinadas especies, etc. En ella emergen con claridad algunos nombres, así como la experiencia política de las agrupaciones de verdes o ecologistas.

De los múltiples nombres que se destacan, algunos personajes sobresalen como Arne Naess, que desde 1972 advierte «que una amplia transformación espontánea estaba teniendo lugar en la consciencia humana, en especial en los países industrializados» (12, p.51). Esta transformación es bautizada por Naess como ecocentrismo. También es posible destacar a Murray Bookchin y su ecología social (12, p.70), la que hacia fines de los años 80 adquiere una forma sistemática. Los contenidos fundamentales de su ecología social se estructuran alrededor de tres ejes: la diversidad, la espontaneidad y la visión no jerárquica de la realidad. La ecología social se orienta, en términos políticos y sociales hacia formas comunitaristas de organización. Interesante nos parece transcribir brevemente las críticas de Bookchin al ambientalismo: «1)El ambientalismo designa una 'perspectiva mecanicista e instrumental' de la naturaleza; 2) tiende a reducir la naturaleza a un depósito de recursos naturales...; 3) El ambientalismo zanja la tensión entre la humanidad y la naturaleza por la vía de una tregua más que de un equilibrio permanente...; 4) El ambientalismo no cuestiona la premisa básica de la sociedad contemporánea: que la humanidad debe dominar la naturaleza, sino que la favorece mediante el desarrollo de técnicas para reducir los impactos de la irreflexiva expoliación del medio ambiente». (12, p.65). En esta galería de nombres también tienen su lugar Jonas, mencionado más arriba.

El ecologismo ha sido objeto de múltiples ataques. Estos van desde las acusaciones de constituir un nuevo y peligroso fundamentalismo, de una evidente cercanía con los contenidos del nazismo, de marxistas reconvertidos (eslogan preferido de los sectores autoritarios en América Latina) hasta ser transformados en los representantes privilegiados de la cultura de la muerte y de la falta de respeto de la vida como una valor incuestionable.

En el marco de estas críticas se desarrolla el ambientalismo como la más seria tentativa de integrar el desafío ambiental al sistema-mundo. Desde sus orígenes esta corriente se encuentra ligada "a la maquina institucional creada por los gobiernos en Estocolmo" destacándose su "neutralidad frente a las relaciones del hombre con la Naturaleza, su automático acomodo al modelo económico, político y social fundado en el industrialismo, su compromiso con la historia de antropocentrismo tejida por la Modernidad y su ciega confianza en los métodos de la ciencia y la técnica. Su opción, en palabras de Lynton $\mathrm{K}$. Caldwell, ha sido "aceptar las realidades políticas y económicas de cada momento y buscar la mediación y el compromiso de las fuerzas tecno-económicas dedicadas a la 
transformación medioambiental y al desarrollo de los recursos» $(12, \mathrm{p} .37)$.

A través del ambientalismo se ha ido configurando en el plano político una red de instituciones que Caldwell llama "estructuras institucionales que se ocupan del hombre-enla-biósfera"(12, p.38) las que incluyen los gobiernos nacionales, el Programa de las Naciones Unidas para el Medio Ambiente, redes de organizaciones no gubernamentales (ONG) y organizaciones intermedias, con un estatuto público y privado. Estas instituciones que se relacionan estrechamente con el sistema, dadas sus fuentes de financiamiento, conservan vínculos estrechos con éste y privilegian el protagonismo de los técnicos, en especial de los economistas, a los que les compete "introducir la temática ecológica en el mercado" (12, p.39). Se trata de ponerle precio al medio ambiente, de desarrollar sus bases económicas a fin de volverlo relevante.

Independientemente del lema según el cual es mejor hacer algo que nada, es difícil negar que en el desarrollo de estas bases económicas la temática ecológica pasa a segundo plano. La prioridad es concedida al crecimiento económico y al progreso social. Incluso la noción de desarrollo sustentable que se pensaba cómplice de la emergencia ambiental se desvía de sus intenciones primeras para privilegiar el crecimiento, con el objeto de conseguir la equidad, restringiendo los temas ambientales a la "simple calidad de vida" (12, p.41); «la sustentabilidad asi entendida no tiene problemas para validar el total reemplazo de los bosques nativos de una región, a condición de que la superficie removida sea completamente reforestada, aunque sea por especies exóticas. De esta forma, no sólo se cumple con el deber de crecer, por la vía de la exportación, sino que además, mediante la reforestación, se asegura que en el futuro existirán los recursos necesarios para continuar la explotación. El mismo criterio puede usarse para estimular la extracción pesquera, el desarrollo ganadero» $(12, \mathrm{p} .42)$. Es claro que en esta forma de ver las cosas la pérdida de biodiversidad no es considerada con seriedad y que sobre la base de este espíritu es posible explicarse el tema de las "vacas locas" y la utilización de hormonas y antibióticos en la producción de animales para el consumo diario.

La conversión de la temática ambiental en un problema económico, condición para introducirla en el sistema-mundo, parece más bien una manera elegante $\mathrm{y}$, al mismo tiempo, ideológica de no plantearse la relación entre capitalismo ${ }^{\mathrm{v}}$ y crisis ecológica. Tanto más que es necesario reconocer que en las condiciones actuales la exigencia ecológica se presenta como un escollo difícil de resolver para este sistema económico.

La relación de la emergencia ambiental es evidente con «dos aspectos elementales del capitalismo histórico. Uno es bien conocido: el capitalismo es un sistema que tiene una necesidad imperiosa de expansión en términos de producción total y en términos geográficos, a fin de mantener su objetivo principal, la acumulación incesante. El segundo aspecto se toma en cuenta menos frecuentemente. Para los capitalistas, sobre todo para los grandes capitalistas, un elemento esencial en la acumulación del capital es dejar sin pagar las cuentas» (13).

Las ganancias de un negocio cualquiera corresponde "al margen existente entre el precio de venta y el coste total de la producción, es decir, el coste de todo aquello que es necesario para colocar ese producto en punto de venta" (13, p.3). Los costes totales se encuentran limitados, por un lado, por el precio del trabajo, el que ha aumentado de manera paulatina y por el otro lado, de los otros costes no laborales. La reducción de estos últimos recaen normalmente sobre el Estado y/o la sociedad. "A lo largo de la historia... los

\footnotetext{
iv Espero que nadie se escandalice con la expresión capitalismo que antes de la caída del muro de Berlín era considerada casi como un posicionamiento político. Hoy es simplemente el único régimen existente.
} 
gobiernos han permitido que las empresas no asuman muchos de sus costes, renunciando a requerirles que lo hagan. Los gobiernos hacen esto, en parte, poniendo infraestructuras a su disposición, y, posiblemente en mayor parte, no insistiendo en que una operación productiva debe incluir el coste de restaurar el medio ambiente para que éste sea preservado" $(13, \mathrm{p} .4)$. Dos tipos de operaciones se relacionan con esta preservación: la primera "consiste en limpiar los efectos negativos de una actividad productiva (por ejemplo, combatiendo las toxinas químicas subproducto de la producción o eliminando los residuos no biodegradables). El segundo tipo consiste en invertir en la renovación de los recursos naturales que han sido utilizados... Los movimientos ecologistas han planteado una larga serie de propuestas especificas... En general, estas propuestas encuentran una resistencia considerable por parte de las empresas" (13, p.4).

Desde el nacimiento de la emergencia ambiental nos encontramos, según Wallerstein, ante tres alternativas: "Una, los gobiernos pueden insistir en que todas las empresas deben internalizar todos los costes y, nos encontraríamos de inmediato con una aguda disminución de beneficios... Dos, los gobiernos pueden pagar la factura de las medidas ecológicas (limpieza y restauración más prevención), utilizando impuestos para ello. Pero si se aumentan los impuestos... o bien se aumentan sobre las empresas, lo que conduciría a la misma reducción de las ganancias, o bien se aumentan sobre el resto de la gente, lo que posiblemente conduciría a una intensa rebelión fiscal... Tres, podemos no hacer prácticamente nada, lo que conduciría a las diversas catástrofes ecológicas... Hasta ahora, la tercera alternativa es la que ha predominado" $(13$, p.5).

Los países del hemisferio Norte, incapaces de tomar las decisiones que se imponen han tratado de ganar tiempo, descargando los residuos en el Sur o imponiendo al Sur de posponer su desarrollo, forzándolos "a aceptar severas limitaciones a la producción industrial o la utilización de formas de producción ecológicamente más saludables, pero también más caras" $(13, \mathrm{p} .5)$.

El ambientalismo, legitimado con el lema es mejor hacer algo que nada ha sido incapaz de instaurar la crisis ambiental como un hecho o un acontecimiento real $e$ independientemente de la sensibilidad del lector nos parece evidente que el esquema anteriormente expuesto permite comprender la posición asumida por el gobierno de Bush a propósito del Protocolo de Kioto.

Entretanto, es decir, al lado o al margen de estas diferentes puestas en relato, los estudios se acumulan y se suceden. Sobre el particular un texto reciente de la ONU señala que entre los peligros modernos para la salud debidos al medio ambiente "cabe mencionar la contaminación del agua en las zonas pobladas, la contaminación del aire en las zonas urbanas, la falta de control de los materiales de desecho sólidos y peligrosos, los riesgos químicos y los peligros radiactivos, la deforestación y los demás problemas vinculados con los cambios ecológicos y climáticos, así como con el agotamiento del ozono en la estratósfera" (14, p.42) Conviene destacar que "tanto en los países desarrollados como en los países en desarrollo uno de los grandes peligros para la salud es la contaminación del aire, especialmente las partículas en suspensión, que se calcula causan cerca de 3 millones de muertos por año en todo el mundo (OMS - 1997)" (14, p.p.42-43).

En la Jornada Virtual, diario Mexicano, se señala el 14 de enero del 2002 que, según datos oficiales, "la violación de las normas de calidad del aire durante 321 de los 365 días del año ocasiona la muerte prematura de alrededor de 35 mil personas-96 al día-en la Zona Metropolitana del Valle de México... Si en la ZMVM los niveles de ozono estuvieran dentro de la norma, se evitarían al año 29 mil casos de admisiones hospitalarias y más de 132 mil visitas a salas de emergencias por males respiratorios, la perdida de productividad y bienestar equivalente a 39 millones de días de actividad restringida en adultos, más de 20 mil 
ataques de asma y 2 mil casos de sintomas en niños", etc., etc.

Por otra parte, la lectura diaria y atenta de internet entrega cada día datos sobre la temática ambiental que refuerzan la idea que la heurística del miedo es peligrosa teóricamente, pero, desgraciadamente cercana a la realidad de nuestro mundo, a lo menos, para quienes buscan entenderlo desde su dimensión individual limitada.

El breve recorrido anterior nos permite plantear un cierto número de afirmaciones. En primer lugar, es poco probable que la bioética haya podido, si lo hubiera querido, cambiar la puesta en relato de la temática ambiental. En los años en que este proceso acontecía ella era aún incipiente. En segundo lugar, es claro que la opinión pública, como una construcción de los centros de opinión, se encuentra sensibilizada con la temática ecológica. Pero, dividida entre el deseo y la necesidad de más bienes materiales y los aspectos exteriores de un medio ambiente sano, no logra acceder a una voluntad política activa. Prefiere confiar ciegamente en los milagros de la tecnociencia. En tercer lugar, en el campo de la bioética se ha producido una defensa de los aspectos más nobles y relevantes de la tecnociencia, que no es, por esencia, la responsable de la crisis ecológica. Finalmente, la degradación ecológica es un dato indudable del futuro. Ella impondrá, en un porvenir no lejano, limitaciones y auto-limitaciones importantes. Que éstas se establezcan en el respeto de la justicia y de la autonomía es un deseo compartido por muchos. ¿Quién podría dudar que ésta es también una tarea que le compete a la bioética?

\section{Observaciones sobre la nocividad alimentaria}

La nocividad alimentaria se inscribe en el horizonte del concepto de seguridad alimentaria elaborado en múltiples textos y conferencias por la FAO, es decir, es parte de la reflexión y de la preocupación política sobre el estado de la alimentación en el mundo. Por un lado, se trata de resolver el acceso de las poblaciones a las dosis nutritivas consideradas como necesarias a la preservación y reproducción de la vida. Por otro lado, como necesidad de generar regulaciones que impidan que este acceso sea fuente de enfermedad y perturbación de la vida. En el mundo actual esta doble dimensión del acceso se encuentra complicada por un desequilibrio estructural: hay poblaciones confrontadas a la morbilidad por ausencia de acceso y otras por exceso y mala alimentación.

Como se puede constatar intuitivamente, el concepto de seguridad alimentaria es muy vasto, con evidentes dimensiones interdisciplinarias, puesto que se encuentran implicadas directamente temáticas tales como la economía, la demografía, las técnicas y la tecnociencia, la política, etc. La manera como la ética y la bioética se integran a esta preocupación plantea inmediatamente una serie de exigencias y desafíos: es necesario salir del lenguaje profesional -en ciertas circunstancias particularmente etéreo-y abrirse a otros discursos y argumentaciones, pero, al mismo tiempo, nuestros discursos y argumentaciones están obligados a comprometerse con una realidad difícil de negar, ya sea por el silencio o la omisión.

En estas observaciones abordaremos sólo dos temáticas de la nocividad alimentaria: el tema de los transgénicos y una tentativa, a la vez reflexiva y práctica, de conexión de personas trabajando en el ámbito de la bioética con otras comprometidas en las asociaciones de consumidores. En realidad las dos temáticas pueden fundirse en una sola. En la medida en que los transgénicos constituyen una experiencia relativamente irreversible conviene examinar brevemente las peripecias y aventuras de la regulación, las lecciones que se imponen y la real capacidad de la ética y la bioética de orientar las prácticas en una dirección u otra. Esta perspectiva crítica constituye también una nueva manera de interrogar el sistema-mundo 
y las referencias con que éste dice regirse.

"Un alimento genéticamente modificado o transgénico es aquel al que, por medio de una modificación genética, se le transfiere artificialmente la información especifica de un tipo de organismo a otro. Por ejemplo, de un pez a un tomate o de un químico a una planta de soya... Algunas plantas poseen un gen que las hace resistente a herbicidas, insectos, insecticidas, al frío, al tiempo, etc. Y se dice que en general mejoran la calidad de los productos" (15, p.27). Las críticas de las asociaciones de consumidores han sido: los OGM (organismos genéticamente modificados) representan un aumento de los peligros para los consumidores; tienden a provocar la pérdida de la diversidad genética en la agricultura; el aerosol genético amenaza el provenir de la agricultura; aumentan los riesgos de la agricultura puesto que crece su uniformidad genética; pueden provocar contaminación genética; pueden provocar la aparición de super plagas; pueden matar insectos benéficos para la agricultura; pueden afectar la vida microbiana en el suelo; los efectos de los transgénicos en la naturaleza son irreversibles; pueden provocar la caída de la producción o el alza de sus costos; nadie quiere asumir la responsabilidad por los peligros de los transgénicos; las variedades transgénicas no son más productivas que las convencionales o que muchas de las tradicionales; los transgénicos representan un peligro para la seguridad alimentaria de los países en vías de desarrollo; hay otras alternativas más eficientes y sin los riesgos que significan los transgénicos; los derechos de los consumidores no han sido respetados $(10)$.

Las críticas de las asociaciones de consumidores han sido respondidas de múltiples maneras, pero las divergencias no han sido científicamente zanjadas, en el sentido de un consenso satisfactorio para los sectores implicados en la discusión. Pero ello no constituye una sorpresa puesto que la evaluación de muchas de las interrogantes planteadas sólo tiene sentido en la perspectiva de un futuro próximo o lejano. Lo que es claro es que una vez que los transgénicos han sido diseminados en la naturaleza es imposible poner límites a su expansión. Lo que tiene consecuencias importantes desde el punto de vista de la interpretación que podemos hacer del proceso social denominado regulación. Baste con señalar que en la Jornada Virtual del 24 de enero del 2002 se podía leer que "estudios de la Secretaría del Medio Ambiente y Recursos Naturales... sobre la presencia de maíz transgénico en las siembras del grano tradicional en la sierra de Oaxaca o en Puebla no sólo confirman la presencia de ese organismo genéticamente modificado sino que advierten que 'no es un hecho aislado y puede ser generalizado' en otras regiones de México, lo cual representa un 'serio problema'... Entre las consecuencias que podría tener este tipo de contaminación está que los trasgenes migren a los parientes silvestres del maíz -los teocintles-, con lo que se contravienen los compromisos internacionales de México asumidos en la Convención de Diversidad Biológica".

En la misma Jornada Virtual del 2 de marzo del 2002 se informa que esta contaminación "fue nuevamente comprobada... habría zonas con hasta $35 \%$ de presencia de fragmentos de trasgenes en maíces criollos... Ante estos datos, un puñado de cientificos en países del Norte cercanos a la industria, han dedicado cuantiosas horas y esfuerzos a decir consecutivamente que la contaminación no existía porque el método de análisis... tuvo errores, mientras ignoraban convenientemente los informes del gobierno mexicano... que confirmaron dichos datos. Al ir comprobando que los nuevos informes y pruebas corroboran los anteriores y que lo más seguro es que lo van a seguir haciendo, siguen intentando llevar el debate hacia metodologías de detección y méritos científicos, pero avizoran el hecho de que la contaminación es inocultable”.

Las discusiones y polémicas sobre los transgénicos se concentraron en un punto: las eventuales consecuencias que los transgénicos podían tener sobre la salud de las personas. 
Frente a la imposibilidad de probar en el presente la veracidad de este riesgo los transgénicos ganaron paulatinamente terreno en el mundo. El único riesgo palpable en estas discusiones y polémicas parece ser la impotencia de aquellos que osan oponerse a ciertos progresos sustentables. Agregando que son sustentables porque producen beneficios y logran, sin mayor sobresalto, transformar en burócratas del campo a los campesinos y agricultores de otrora. Al respecto ya tuvimos la ocasión de escuchar los descargos de ciertos agricultores frente a la ola de críticas provocadas por las vacas locas: "nosotros también somos consumidores de vacunas, de alimentos industriales cuyo contenido no podemos evaluar, de plaguicidas, de hormonas de crecimiento, de antibióticos".

La mayor parte de las otras temáticas evocadas durante la polémica sobre los transgénicos quedaron al margen de los parámetros que elaboraron las posibles opciones y soluciones reclamadas por los $O G M$. Como si no le correspondiera al proceso social de regulación encargarse de ellos. En las grandes decisiones en las que se juega el porvenir de considerables inversiones la sociedad debe fiarse una y otra vez a la lógica del mercado.

Una vez que los transgénicos pasaron a través de los diferentes mecanismos de regulación se trató de salvaguardar la libertad de los consumidores por medio del etiquetado. Se pensó que este procedimiento, metafóricamente próximo al consentimiento informado o al derecho a la información, permitiría conectar las decisiones sobre los transgénicos con la democracia. El consumidor informado podría sancionar, a través del consumo, la viabilidad económica y comercial de los OGM.

Conviene no olvidar que el etiquetado como procedimiento de regulación fue obstaculizado durante mucho tiempo en los países desarrollados, a pesar de que los productos se encontraban en los diferentes lugares de venta $\mathrm{y}$, continúa siéndolo en la mayor parte del mundo. Lo que convierte la confianza en este proceso de regulación en una ilusión inocente, sobre todo si se valora adecuadamente la increíble presión que ejerce sobre los consumidores la propaganda y la publicidad comercial.

Detrás de esta confianza se erige una conceptualización más fina sobre la regulación del consumo. Se habla de patrones de consumo (17) y de una dinámica, dotada de un cierto poder, que sostiene el accionar de los consumidores. Esta dinámica, presente de forma espontánea en las opciones de la casi totalidad de los consumidores del mundo se expresa a través de tres términos: acceder, optar, regular. Es evidente que la incapacidad de acceder a un consumo anula esta dinámica. En donde esta capacidad existe, la opción y adhesión de los consumidores a determinados productos o el rechazo a otros, genera señales que el productor debe necesariamente respetar. Esta opción sería equivalente a un poder creciente de regulación por parte de los consumidores. Esto se vuelve relativamente ilusorio en el caso de los transgénicos por el aumento de la presencia de OMG en productos que consumimos creyendo que no los contienen. El etiquetado es hoy incapaz de identificar completamente la presencia de los OMG, lo que impide optar verdaderamente.

Al respecto Klein describe una situación límite, que reduce al mínimo la capacidad de regulación de los tres términos anteriormente nombrados: "Loblaws, la cadena de supermercados más grande de Canadá (con $40 \%$ del mercado), envió una carta a todos sus proveedores de alimentos sanos... informando que ya no estaba permitido poner que los alimentos eran "libres de OGM". Los ejecutivos de la compañia argumentaban que no hay manera de saber qué está auténticamente libre de OGM" (18).

En el mismo artículo se relata que un agricultor de Canadá "fue demandado por Monsanto después de que semillas de canola GM volaron a su campo de cultivo desde camiones que transitaban por ahi y desde 
cultivos vecinos. Monsanto dice que cuando las semillas enraizaron, Schmeiser estaba robando su propiedad. El tribunal estuvo de acuerdo y hace dos meses le ordenó al agricultor que pagara 20 mil dólares a la compañia, además de los costos legales" (18).

En la perspectiva de lo dicho no sólo aparece claro que el proceso de regulación ha sido frágil e incapaz de imponer sus normas, sino que la historia de los transgénicos da cuenta de la existencia de poderes fácticos que ejercen su influencia desde las múltiples redes que constituyen y que dada su complejidad o dimensión planetaria sobrepasan a cualquier humilde consumidor. Los lobbys han hecho su trabajo sin ninguna dificultad. Monsanto, una de las multinacionales más poderosa en el rubro, creó su propia fundación, en el marco de las discusiones y polémicas, para procurar una adecuada información, lo que sobrepasa el accionar de cualquier otra ONG. Los especialistas, en este contexto, a no ser de considerarlos como una encarnación del filósofo rey platónico o un burócrata al estilo hegeliano, también son constantemente sobrepasados.

La decisión a favor de los transgénicos se inspiró de otro argumento ético, relativamente falso, que nunca fue abordado seriamente: los transgénicos son la única solución para un mundo futuro, donde, a causa del aumento continuo de la población los alimentos escasearán y el hambre se apoderará del planeta. Relativamente falso como parámetro, puesto que las proyecciones sobre la población mundial son menores a las de hace algunos años, porque la agricultura tradicional, gracias a sus progresos técnicos aún produce alimentación suficiente para todo el mundo, porque el problema de la seguridad alimentaria es un problema político y de justicia social. Pero lo más increíble es que los transgénicos no fueron producidos para los pobres ya que se venden prioritariamente en los mercados de los países ricos y su objetivo último es competir con las otras formas de producir alimentos y eventualmente, en un futuro, desplazarlos completamente.

En otros textos (19) en los cuales nos interesábamos en el establecimiento y desarrollo de un diálogo entre las asociaciones de consumidores (Oficina Regional para A. Latina y el Caribe) y la ética/bioética nos comprometimos en un análisis más fino sobre la idea de regulación y patrones de consumo. La noción de un desplazamiento del poder de los productores a los consumidores nos pareció particularmente audaz. En estos textos nos pareció importante proponer otras referencias.

En primer lugar, desde el punto de vista del consumo la relación entre productores y consumidores es asimétrica. Los productores representan el polo activo, que quisiéramos calificar casi de ontológico, por su capacidad de alterar y modificar la realidad. Mientras que los consumidores representan el polo pasivo, adecuadamente enunciado por la expresión consumo/consumir. La regulación, para las asociaciones de consumidores, se asemeja a una loca carrera contra el tiempo con el fin de comprender la significación de un producto y su impacto sobre el sistema mundo, es decir, con el objeto de evaluar su nocividad.

En segundo lugar, el consumo y el sistema mundo es casi simétrico. En la perspectiva del imperio de las marcas el fenómeno del consumo es parte de la cultura y en este contexto juega un papel prioritario en la socialización de los individuos. Incluso esta nueva cultura ha perturbado profundamente los saberes y su capacidad crítica. La pregunta pertinente aquí consiste en saber si las asociaciones de consumidores son capaces de encargarse de la gestión y el pensamiento del espacio social representado por la regulación, dado que el consumo en el mundo actual abarca lo que debería ser abordado por la política. Entendida ésta como la dimensión donde, a lo menos en un contexto democrático, se define y se acota lo deseable, tanto desde un punto de vista individual como colectivo. Esto no constituye una crítica a las asociaciones de consumidores. En realidad éstas reconocen la íntima relación entre consumo y sistema 
mundo, puesto que incluyen en la evaluación sobre la nocividad las variables ecológicas y la explotación de las poblaciones pobres involucradas en la elaboración de determinados productos con el fin de bajar sus costos.

$\mathrm{Si}$ en términos de fuerzas sociales, se quisiera adecuar el accionar de los consumidores al verdadero desafío de la regulación deberían generarse redes que aseguren la participación en este debate de otras organizaciones donde la gente se agrupa según su inserción social. Si esto aconteciera la política o sus debates fundamentales se explicitarían en torno al consumo, a sus posibles nocividades en el sentido que lo entienden las asociaciones de consumidores y no me cabe duda que la discusión sobrepasaría el tema de la regulación y se concentraría en la conexión entre libertad y consumo. Es decir, en la gestión común de un mundo que les pertenece por igual a todos aquellos que vivimos, así como a las generaciones futuras.

En tercer lugar, si la ética y la bioética se comprometieran con la preocupación representada por las asociaciones de consumidores y otros actores sociales sólo podrían hacerlo a través de un axioma y de tres opciones no triviales. Respecto del axioma éste podría expresarse como sigue: la ética/bioética constituye, de manera real o difusa, un espacio social en el cual existe y se reproduce una masa crítica. Éstas poseen la legitimidad de inmiscuirse en los temas que plantean interrogantes centrales para el mundo contemporáneo, más allá de su eventual involucramiento en la elaboración del orden mundial, como lo señalábamos al comienzo de este texto.

Las tres opciones no triviales donde ética/bioética podrían comprometerse con la preocupación de las asociaciones de consumidores podrían enunciarse de la siguiente manera: a) Invertir una parte de su propia legitimidad en el acompañamiento de las propuestas y acciones de instituciones que constituyen esa nebulosa denominada sociedad civil. Es evidente que en este acompañamiento nuevas significaciones de la ética y la bioética respecto del mundo actual deben explicitarse; b) Este acompañamiento no es sólo una adhesión a causas nobles, puesto que a través de formas particulares de argumentación, acumuladas por la ética y la bioética, se trata de evitar cualquier forma de banalización y burocratización de las temáticas. El carácter interdisciplinario de la bioética se acomoda bien con el trabajo en redes y asociaciones comunitarias, puesto que las distintas dimensiones presentes en argumentaciones y polémicas son parte de su trabajo cotidiano.

En el rechazo de la banalización se expresa algo de lo dicho anteriormente sobre el destino de hechos y acontecimientos. En el caso de los transgénicos le habría competido a la bioética sostener el imperativo de prudencia como válido, independientemente de la dificultad de procurar en el presente pruebas sobre la nocividad alimentaria de los transgénicos. Se trataba simplemente de no banalizar el acontecimiento representado por los OGM, es decir, impedir que la sociedad desconociera que los transgénicos se encuentran en el origen de una serie causal de hechos con consecuencias de todo tipo; c) Pero, sin duda alguna, el involucramiento más importante puede producirse en otra dimensión. En la medida que la bioética es en la sociedad actual un recurso reflexivo, una capacidad de elucidación de temáticas complejas, es posible esperar que ciertos desafíos sociales y culturales puedan ser contextualizados y pensados en el espacio que ella ocupa. En pocas palabras, frente al orden mundial, que delante de cada hecho momentáneamente significativo pide procedimientos y soluciones, inevitables en determinadas circunstancias, se trata de preservar para la bioética la tarea de elucidar el sentido. Éste no sólo se enuncia como contextualización, conexión de temáticas aparentemente alejadas. El sentido también tiene implicaciones al nivel de la esperanza y de la capacidad de querer y desear que las cosas sean de manera diferente.

Ahora pensamos que es el momento de 
volver al comienzo de nuestro texto para destacar un camino al interior de la bioética que se desprende de lo anteriormente propuesto.

\section{En el horizonte de la nocividad: la perti- nencia y el necesario pluralismo de la bioética}

Siempre es necesario reunir en algún punto lo acumulado para dar el paso siguiente. No hay duda que la intervención de la bioética en el dominio de la nocividad, cualquiera sea la evaluación, es legítima. Su intervención ha sido frágil y plagada de supuestos no pertinentes. Muchos de sus discursos sobre el tema se han propuesto simplemente porque la legitimidad de pertenecer al mundo de la bioética abre las puertas de ciertas publicaciones. El esmerado respeto a una cierta neutralidad y objetividad ha producido discursos políticamente correctos que poco o nada tienen que ver con las temáticas abordadas. En otros casos, reflexiones sobre temas cruciales para la nocividad, adecuadas y pertinentes, han contribuido en la ausencia de conexiones con la puesta en relato de las opciones a la inflación de los discursos o al desarrollo sin límite de imperativos contradictorios.

Pocas son las reflexiones del mundo bioético donde se examine su pertinencia respecto de las temáticas que aseguran su legitimidad. La historia de la nocividad es un tema donde las lecciones acumuladas son parte de la posición que se adopta sobre la nocividad. Más aún, la experiencia acumulada constituye un límite crítico que interroga y desestabiliza la inserción de la bioética en el mundo actual y que sólo puede redundar en un incremento de su pertinencia. Ella demuestra que los mecanismos de regulación, legítimamente consensuados, no funcionan ${ }^{\mathrm{v}}$ en determinadas circunstancias. Asociar los nudos decisionales con argumentaciones éticas tampoco es una garantía. Incluso, procedimientos democráticos, como el deseo y las preferencias de la gente, no alteran necesariamente las decisiones. El discurso económico se cierne habitualmente en el horizonte como si fuera el doble de la naturaleza. Lejos estamos de aquellas épocas en que las políticas económicas constituían el centro de la discusión política, en la medida en que la política, como lo decía Castoriadis, en el registro de la autonomía como una exigencia encarnada, es discusión y polémica permanente sobre lo participable y lo distribuible. E1 transcendentalismo, es decir, la existencia de aplanadoras, discursos y lógicas que sobrepasan los sujetos no es, en el mundo actual, solamente el privilegio de los fundamentalismos. Las instituciones de la bioética son capaces de regular la tecnociencia sobre una serie de temáticas importantes. Pero, ¿quién regula la tecnociencia desde el interior? No sólo el dinero, pero vaya el papel que juega.

La nocividad ambiental y alimentaria debiera remecer la bioética puesto que concierne a la biopolítica como dimensión central y constitutiva de la bioética. Lo que se juega es el estar en la tierra de los seres humanos, es decir, aquello en que ineluctablemente debemos participar y que quisiéramos construir colectivamente, preservando la posibilidad de auto institución de la sociedad, lo que es equivalente a preservar y promover nuestra autonomía individual. ¿Una utopía? Casi. Puesto que sabemos que toda sociedad socializa sus individuos en función de las significaciones que posee. En muchos casos, lo constatamos todos los días, bajo el imperativo del olvido; olvido de sí, de los otros, de las verdades de nuestro cuerpo y de nuestra corporalidad, de lo que acontece, de lo que aconteció, de lo

\footnotetext{
v "Las superficies cultivadas con OGM han progresado de un 19\% durante el año pasado... Desde 1996 las superficies en OGM han sido multiplicadas por treinta. A fines del 2001 la superficie cultivada alcanzaba 52,6 millones de hectáreas contra 44,2 millones en el 2000 y 1,7 en 1996 ...cuatro países concentran la casi totalidad (99\%) de las superficies cultivadas en OGM: Los Estados Unidos con un 68\% ... Argentina con 22\%, Canadá con un $6 \%$ y China con un 3\%". Les Echos, del 23/1/2002.
} 
agradable que es vivir la propia vida como una película, a la cual podemos cambiarle el guión cuando queramos. Aquí interviene, además, lo dicho más arriba sobre el nuevo régimen de la ficción. Pero no prolonguemos indebidamente el pánico y la auto flagelación. Como lo dice Marc Augé este nuevo régimen de la ficción es un acto político y también se disuelve a través de actos políticos que se construyen sobre la base de hechos y acontecimientos que efectivamente determinan nuestra vida individual y colectiva.

La bioética reúne en un mismo impulso reflexión, elucidación y transformación. Este impulso se materializa en prácticas diversas que se desarrollan en la perspectiva de una historia. Ciertas temáticas determinan hitos en su historia, marcan su devenir. Postulo que las nocividades constituyen un punto de inflexión. Por el momento identifico cuatro consecuencias que grafican esta inflexión: 1) La reflexión sobre la nocividad es, al mismo tiempo, comprensión de lo que acontece y, tímidamente, ejercicio libre y comprometido, sobre el estado presente y futuro del mundo. En esta reflexión juega un papel central la construcción de figuras e imágenes de una sociedad respetuosa de la ecología; 2) Elucidar es prolongar la reflexión en el campo de lo social y lo cultural. El destino de nuestras reflexiones no sólo se orienta en la perspectiva de un poder y un orden. El éxito de la bioética también se mide por su capacidad de permear el discurso social empoderando los actores sociales. Elucidar es inducir nuevos reflejos sociales y políticos, en particular: ¿quién decide qué y por qué?; 3) La relación entre bioética y política debe replantearse con fuerza al interior de la bioética. No nos corresponde recomenzar la aventura de una cierta filosofía política del pasado. Nuestra atención no debe centrarse sobre modelos de lo que sería la mejor política. Simplemente lo que pensamos y decimos es político, implica una evaluación política de lo que vivimos, independientemente de las consecuencias; 4) Finalmente, una temática considerada como un acontecimiento legitima redes que se expresan en textos y discusiones que enuncian nuestro derecho a orientar un campo determinado del saber en una dirección específica.

Sin embargo, todo lo dicho se sostiene en un gran supuesto. Existe, eventualmente, un campo interdisciplinario constituido por temáticas y prácticas diversas que permite una cierta unidad entre bioeticistas de países desarrollados y subdesarrollados, entre latinoamericanos y estadounidenses; de manera menos trivial, entre los que se ganan la vida haciendo clases y los que trabajan en instituciones de todo tipo, incluyendo firmas farmacéuticas u otras. Es aquí donde interviene la noción de pluralismo. Desterrando cualquier forma de pluralismo light, la nocividad es la ocasión de remecer el campo difuso de la bioética con polémicas, que constituyan un cultivo verdadero del pluralismo, identificándolo como motor de nuestro desarrollo, permitiendo colocar también, en el centro de la discusión, la responsabilidad ética y política de cada uno de nosotros. 


\section{Referencias}

1. Wallerstein I. Commentaries. In: Fernand Braudel Center. [On line]. Available from: URL: http://fbc.binghamton.edu/commentr.htm

2. Hardt M, Negri A. Imperio. Barcelona: Paidós; 2001.

3. Klein N. El poder de las marcas. Barcelona: Paidós; 2001.

4. Ladrière J. Del sentido de la Bioética. Acta Bioethica 2000; VI (2): 197-229.

5. Gafo J. Riesgos y ventajas de los alimentos transgénicos. Mensajes 2000; XLIX: 25-32.

6. Hottois G. Aux fondements d'une éthique contemporaine. H. Jonas et H. T. Engelhardt en perspective. París: Librairie Philosophique J. Vrin; 1993.

7. Hottois G. Pour une philosophie de la bioethique. Bioética y Sociedad 2001;1(1): 39-51.

8. Ginzburg C. Indicios. Raices de un paradigma de inferencias indiciales. En: Mitos, Emblemas, Indicios. Barcelona: Gedisa; 1999.

9. Zorrilla S. La fragilidad y la orfandad del pensamiento crítico. Ojo de Buey 1998; 5: 15-20.

10. Augé M. Ficciones de fin de siglo. Barcelona: Gedisa; 2001.

11. Augé M. La guerra de los sueños: ejercicios de etno-ficción. Barcelona: Gedisa; 1998.

12. Aldunate C. El factor ecológico: las mil caras del pensamiento verde. Santiago de Chile: Lom; 2001.

13. Wallerstein I. Ecología y costos de producción capitalistas: no hay salida. 2001. [On line] Available from: URL: www.eurosur.org/ecología/wallerstein230901.htm

14. Naciones Unidas. Población, medio ambiente y desarrollo. Informe conciso. Nueva York: Naciones Unidas; 2001.

15. Paz S. ¿Qué son los alimentos transgénicos? Revista Sentidos. 2000; 4(5): 27- 29.

16. Paz S. La sociedad civil organizada dice no a los transgénicos. Revista Sentidos 2000; 4 (5): $21-6$.

17. Blomeier H. Los patrones de consumo. Revista Sentidos 2000; 4(5): 16- 20.

18. Klein N. La invisible guerra de los organismos modificados. 2001. [On line]. Available from: URL: www.eurosur.or.

19. Dides C, Hevia A, Zorrilla S. Alimentación, ética y consumo. Revista Sentidos 2000; 4(5): 4-15.

20. Zorrilla S. Desafíos políticos del consumo alimentario. Revista Sentidos 2000; 4(5): 54 - 61 . 